\title{
Parasitism of Sedentary Stages of Heterodera glycines by Isolates of a Sterile Nematophagous Fungus
}

\author{
Patricia Timper, Robert D. Riggs, and Devany L. Crippen
}

Department of Plant Pathology, University of Arkansas, Fayetteville 72701.

Current address of P. Timper: USDA-ARS, Nematodes, Weeds, \& Crops Research Unit, P.O. Box 748, Tifton, GA 31793.

Accepted for publication 20 August 1999.

\begin{abstract}
Timper, P., Riggs, R. D., and Crippen, D. L. 1999. Parasitism of sedentary stages of Heterodera glycines by isolates of a sterile nematophagous fungus. Phytopathology 89:1193-1199.

Isolates of a sterile fungus designated ARF (Arkansas fungus) can be separated into two groups, ARF-C and ARF-L, that differ morphologically and in their ability to suppress numbers of Heterodera glycines on soybean. Our objectives were to determine if the two ARF groups differed in their ability to parasitize juveniles, females, and eggs in the rhizosphere of soybean and to proliferate in soil. The experiments were con-

than did the ARF-C isolates. Suppression of these stages was $67 \%$ for ARF-L and $12 \%$ for ARF-C isolates 14 days after nematode inoculation. When soybean plants containing gravid females were transplanted into fungus-infested soil, ARF-L isolates parasitized 55 to $98 \%$ of nematode eggs, whereas ARF-C isolates parasitized 0 to $22 \%$. In both heat-treated and nonheated soil, the biomass of mycelial mats, a measure of relative proliferation, tended to be greater for ARF-L than for ARF-C isolates. The ability of ARF-L isolates to parasitize a large percentage of both prereproductive stages and eggs of $H$. glycines may contribute to its effectiveness as a biological control agent.
\end{abstract} ducted in a greenhouse using soil infested with homogenized ARF mycelium. The ARF-L isolates parasitized more juveniles and young females
Additional keywords: efficacy, soybean cyst nematode.
A sterile hyphomycete designated ARF (Arkansas fungus) parasitizes all sedentary stages of the soybean cyst nematode Heterodera glycines and suppresses nematode numbers in heat-treated and nonheated soil under greenhouse conditions $(13,20)$. The fungus does not parasitize the motile second-stage juveniles $(\mathrm{J} 2)$ of $H$. glycines. However, once this stage establishes a feeding site in the vascular tissue of the root and becomes immobile, it is presumably susceptible to parasitism. As the nematode matures through the second, third, and fourth stages and into the adult, it progressively swells, eventually breaking out through the root epidermis (4). Most juveniles are embedded within the root tissue, where they are thought to be protected from fungal infection. The female remains sedentary, while the male molts from the fourth-stage juvenile (J4) into a migratory worm. Most eggs are retained within the female body, though some are extruded in a gelatinous matrix outside the vulva. After death, her cuticle hardens and darkens to form a protective cyst around the eggs. Females, and eggs within the cyst and gelatinous matrix, are considered vulnerable to parasitism because they are sedentary and exposed to parasites such as ARF in the soil. A study on the mechanism of cyst penetration and egg infection showed that the hyphae of ARF form a mycelial mat on the outer surface of the cyst wall and penetrate the wall through numerous points under the mat (15). Once inside the cyst, the hyphae are able to penetrate the egg shells directly. The mechanism by which the fungus infects and its virulence toward females and sedentary juveniles are unknown.

ARF is characterized by its ability to infect $H$. glycines eggs, produce sterile white mycelium, and form sclerotium-like structures on cornmeal agar (12). The lack of sexual or asexual spores has

Corresponding author: P. Timper

E-mail address: ptimper@tifton.cpes.peachnet.edu

Publication no. P-1999-1019-03R

This article is in the public domain and not copyrightable. It may be freely reprinted with customary crediting of the source. The American Phytopathological Society, 1999. impeded classification of ARF; however, the presence in the hyphae of a simple septum with a central pore and nearby Woronin bodies strongly indicate that ARF is in the subdivision Ascomycotina (15). Several isolates possessing the characteristics of ARF were collected between 1987 and 1994 from the midsouthern region of the United States (Table 1). Based on morphology of the sclerotiumlike structures, these isolates were placed into two groups (14) designated compact (ARF-C) and loose (ARF-L). Analysis of mitochondrial DNA restriction fragment length polymorphisms (mtDNA RFLP) with three restriction enzymes and two mtDNA probes showed that the isolates belong to four different groups (14). The ARF-C isolates were all within group I. The ARF-L isolates were classified into groups II, III, and IV. These different mtDNA RFLP groups may represent different genera, species, or biotypes.

In addition to morphological and mitochondrial characteristics, the ARF-C and ARF-L isolates differ in their ability to parasitize $H$. glycines eggs on agar and to suppress populations of this nematode on soybean (Glycine max). On agar, ARF-C isolates parasitized more eggs than did ARF-L isolates (14). However, ARF-L isolates were more effective than ARF-C isolates in reducing nematode numbers on soybean (20), suggesting that virulence toward eggs in vitro is not related to the ability of an isolate to suppress nematode numbers in soil. The question then arises, what fungal traits are related to suppression of $H$. glycines numbers in soil? One hypothesis is that the ARF-C isolates are specialized for infecting $H$. glycines eggs, while the ARF-L isolates are specialized for infecting the sedentary juveniles and females. Different enzymes may be required to penetrate the nematode egg shell and cuticle, because egg shells contain a chitin-protein complex, whereas the cuticle contains collagen as the major structural protein (21). Few eggs, parasitized or healthy, were recovered from soybean roots growing in soil infested with ARF-L isolates (20), indicating that the nematodes were killed before eggs were produced. A second hypothesis is that mycelial growth in soil is greater for ARF-L than for ARF-C isolates. Isolates with extensive growth in soil, particularly the rhizosphere, will have a greater probability of contacting nematode hosts than will those with restricted growth. 
Experiments were performed to identify some of the fungal traits related to suppression of $H$. glycines numbers in soil. Our main objective was to compare ARF isolates for their ability to parasitize juveniles, females, and eggs in the rhizosphere of soybean. We predicted that the ARF-L isolates would parasitize more juveniles and females, while the ARF-C isolates would parasitize more eggs. A secondary objective was to compare mycelial growth of ARF isolates in the presence and absence of soybean roots and soil microorganisms.

\section{MATERIALS AND METHODS}

Fungus. The ARF isolates came from infected $H$. glycines eggs collected in the midsouthern region of the United States from 1987 to 1994 (Table 1). The isolates were continuously cultured at room temperature $\left(20\right.$ to $\left.26^{\circ} \mathrm{C}\right)$ on cornmeal or Emerson's YpSs agar (3). In experiments involving soil, fungal inoculum was produced in $250-\mathrm{ml}$ flasks containing $150 \mathrm{ml}$ of sterile unsalted pea juice medium $(2: 3$ [vol/vol] canned pea juice/distilled water). The flasks were inoculated with two homogenized plugs ( $1 \mathrm{~cm}$ diameter) of agar from the leading edge of a culture and placed on a rotary shaker for 7 to 9 days at 20 to $26^{\circ} \mathrm{C}$. Mycelium was harvested from the liquid cultures on a vacuum filter, rinsed three times with sterilized distilled water, and homogenized in water in an electric blender at medium speed for $30 \mathrm{~s}$. Unless otherwise stated, the homogenized mycelium was mixed by hand into an air-dried fine sandy loam (53\% sand, $41 \%$ silt, and $6 \%$ clay; $<1 \%$ organic matter, $\mathrm{pH} 6.5$ in water ) that had been heated while moist to a maximum of $105^{\circ} \mathrm{C}$ for $3 \mathrm{~h}$ to kill most organisms. The concentration of mycelium varied from 2 to $3 \mathrm{mg} / \mathrm{cm}^{3}$ of soil, depending on the experiment.

Nematodes. $H$. glycines race 3 was obtained from a greenhouse population maintained on soybean cv. Lee 74 (used in all experiments involving plants). Nematodes were extracted from the cultures by hand-rubbing roots in water and collecting the cysts on a $250-\mu \mathrm{m}$-pore sieve nested under an $850-\mu \mathrm{m}$-pore sieve. Root and soil debris was removed using centrifugal flotation (9). Eggs were freed from cysts with a tissue grinder, collected on a $25-\mu \mathrm{m}$-pore sieve, and placed in hatching chambers to facilitate emergence of $\mathbf{J} 2$. Each hatching chamber consisted of a slightly concave wire screen with three layers of circular-cut tissue paper laid over the screen that was placed inside a $15-\mathrm{cm}$-diameter petri dish that contained approximately $80 \mathrm{ml}$ of $16 \mathrm{mM} \mathrm{ZnSO} 4 \cdot 7 \mathrm{H}_{2} \mathrm{O}$ to increase the rate of egg hatch (19). Eggs were placed on the tissue, and J2 were

TABLE 1. Isolate characteristics of a sterile fungus (ARF) and parasitism of Heterodera glycines eggs in vitro

\begin{tabular}{|c|c|c|c|c|}
\hline Isolate & ARSEF no. ${ }^{a}$ & $\mathrm{SLS}^{\mathrm{b}}$ & mtDNA group $^{c}$ & Parasitized eggs $(\% \pm \mathrm{SE})^{\mathrm{d}}$ \\
\hline Control & & & & $0.6 \pm 0.3$ \\
\hline MS8 & 5248 & $\mathrm{C}$ & I & $15.7 \pm 6.0$ \\
\hline 908 & 5241 & $\mathrm{~L}$ & II & $20.6 \pm 4.0$ \\
\hline 907 & 5240 & $\mathrm{~L}$ & II & $25.5 \pm 7.7$ \\
\hline 903 & 5238 & $\mathrm{C}$ & $\mathrm{I}$ & $35.4 \pm 0.4$ \\
\hline TN14 & 5243 & $\mathrm{~L}$ & IV & $38.2 \pm 7.6$ \\
\hline TN12 & 5242 & $\mathrm{C}$ & $\mathrm{I}$ & $56.2 \pm 8.7$ \\
\hline KY1 & 5244 & $\mathrm{C}$ & I & $61.0 \pm 7.1$ \\
\hline MS1 & 5245 & $\mathrm{C}$ & I & $75.2 \pm 5.7$ \\
\hline BG2 & 5239 & $\mathrm{C}$ & I & $83.2 \pm 10.3$ \\
\hline MS5 & 5247 & $\mathrm{C}$ & I & $86.8 \pm 3.3$ \\
\hline MS3 & 5246 & $\mathrm{C}$ & I & $96.9 \pm 0.9$ \\
\hline
\end{tabular}

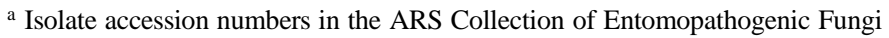
(ARSEF), Ithaca, NY.

b Morphology of sclerotium-like structures (SLS) produced on cornmeal agar: $\mathrm{C}=$ compact, and $\mathrm{L}=$ loose.

c Grouping is based on mitochondrial DNA (mtDNA) restriction fragment length polymorphisms using three restriction enzymes and two mtDNA probes (14).

d Yellow females containing eggs were placed on plugs of mycelium growing on Emerson's YpSs agar. The percentage of eggs parasitized was determined 10 days later. Percentages are the mean \pm standard error (SE) of five replicate mycelial plugs (250 eggs). collected every 3 days by pouring the contents of the petri dish over a $25-\mu \mathrm{m}$-pore sieve and rinsing with tap water. Fresh $\mathrm{ZnSO}_{4}$ was added to the chambers after each collection.

Parasitism of eggs on agar. The egg parasitism assay of Kim et al. (14) was repeated to ensure that the virulence of the ARF-C isolates had not diminished during in vitro culture. Plugs $(1 \mathrm{~cm}$ diameter) from the leading edge of a colony growing on Emerson's YpSs agar were placed mycelium side up on water agar $(1.5 \%)$, and three gravid yellow females of $H$. glycines were placed on top of each plug. Five plugs of an isolate were contained within a single
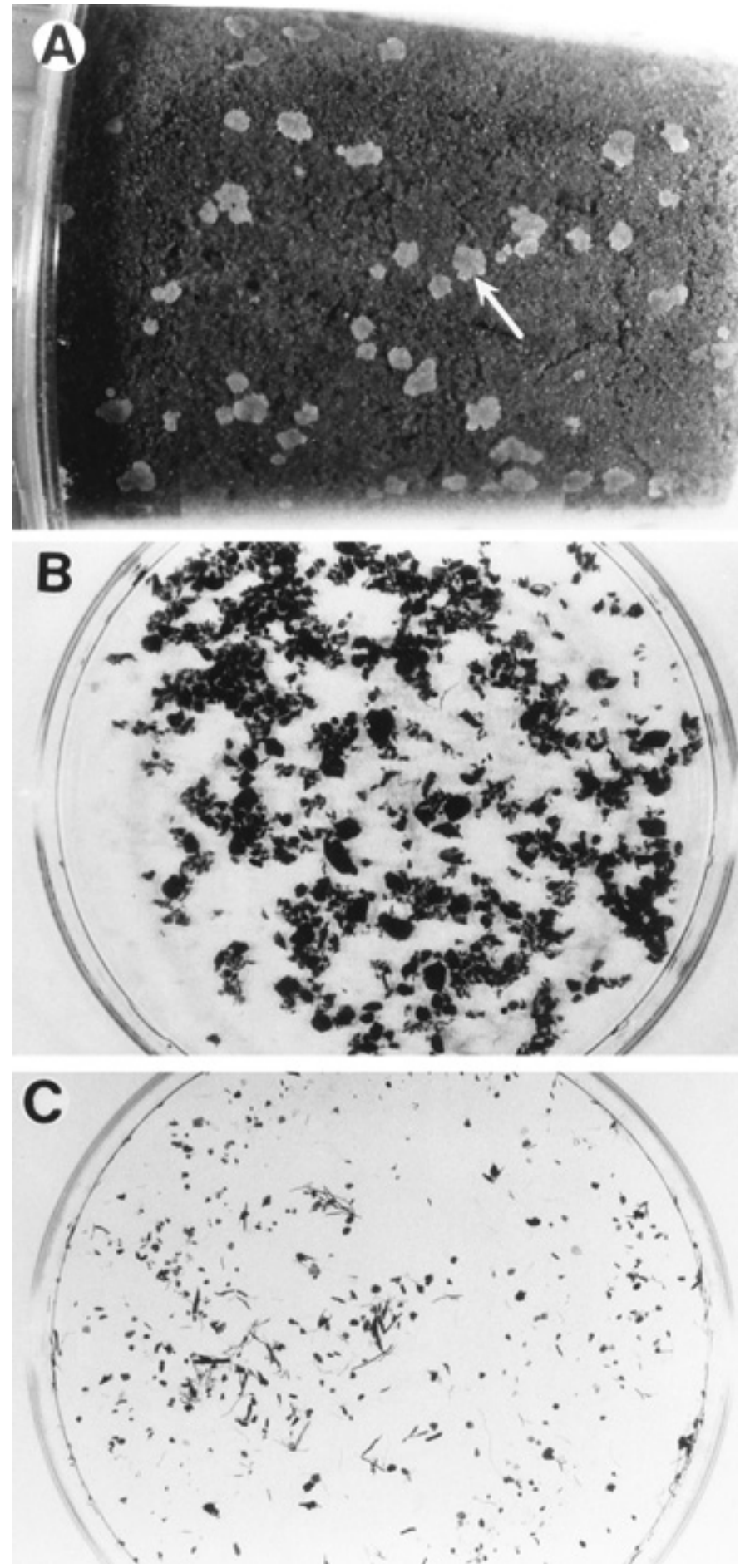

Fig. 1. Mycelial mats formed 10 days after adding homogenized mycelium of ARF to heat-treated soil in the absence of Heterodera glycines. A, Mats forming in soil contained within a $120-\mathrm{cm}^{3}$ plastic cup. B, Mats extracted from soil by wet sieving. $\mathbf{C}$, Debris obtained by wet sieving soil that was not treated with homogenized mycelium of ARF. $\mathbf{B}$ and $\mathbf{C}$, Extracted mats and debris are contained within a 150 -mm-diameter petri dish. 
petri dish. After 10 days, the females from each plug were crushed together in a tissue grinder to release the eggs and the eggs were collected on a $25-\mu \mathrm{m}$-pore sieve. A concentrated suspension of eggs was placed on a slide, covered with a glass slip, and examined at $\times 200$ to $\times 500$ magnification. Percent parasitism was determined by examining the first 50 eggs encountered. Eggs with internal hyphae were considered parasitized. The virulence (percentage of eggs parasitized) of each isolate was tested in only one of three trials: isolates 903, 908, MS1, and TN14 in trial 1; isolates KY1, MS5, and TN12 in trial 2; and isolates 907, BG2, MS3, and MS8 in trial 3. All trials contained a control dish consisting of YpSs agar plugs without fungus. Because the treatments (i.e., ARF isolates) were not randomized or repeated in time, no statistical analysis was performed on the data. Instead, the relative virulence of the ARF-C and ARF-L isolates were compared with the results of a similar assay reported by Kim et al. (14).

Parasitism of sedentary juveniles and females in the rhizosphere. Homogenized mycelium was mixed into heat-treated soil at $2.5 \mathrm{mg} / \mathrm{cm}^{3}$. The infested soil was packed into $50-\mathrm{cm}^{3}$ conical pots $(16.5 \mathrm{~cm}$ long $\times 2.7 \mathrm{~cm}$ inside diameter), and a 7- to 9-dayold soybean seedling was planted in each pot. Control pots were similar to the treated pots except that no mycelium was added to the soil. One week later, a mixture of $454 \pm 32 \mathrm{~J} 2$ ( $\bar{x} \pm$ standard error [SE]) and $151 \pm 10$ eggs was pipetted onto the soil surface of each pot. Plants were maintained in a greenhouse at 27 to $35^{\circ} \mathrm{C}$ with $4 \mathrm{~h}$ of supplemental light per night and watered twice daily. After 7, 14, and 21 days, nematodes were extracted from the roots and examined for parasitism. The method of nematode extraction differed on each sampling day to adjust for the different developmental stages present in the roots. On days 7 and 14, the roots were cut into approximately 3 -cm-long pieces, stained with an acid fuchsin, lactoglycerol solution (1) and homogenized in a blender for $30 \mathrm{~s}$. The nematodes were separated from the root debris using nested 250- and 74- $\mu \mathrm{m}$-pore sieves on day 7 and $850-$ and $74-\mu \mathrm{m}-$ pore sieves on day 14 . On day 21 , roots were hand-rubbed in water and females were collected on a $250-\mu \mathrm{m}$-pore sieve nested under

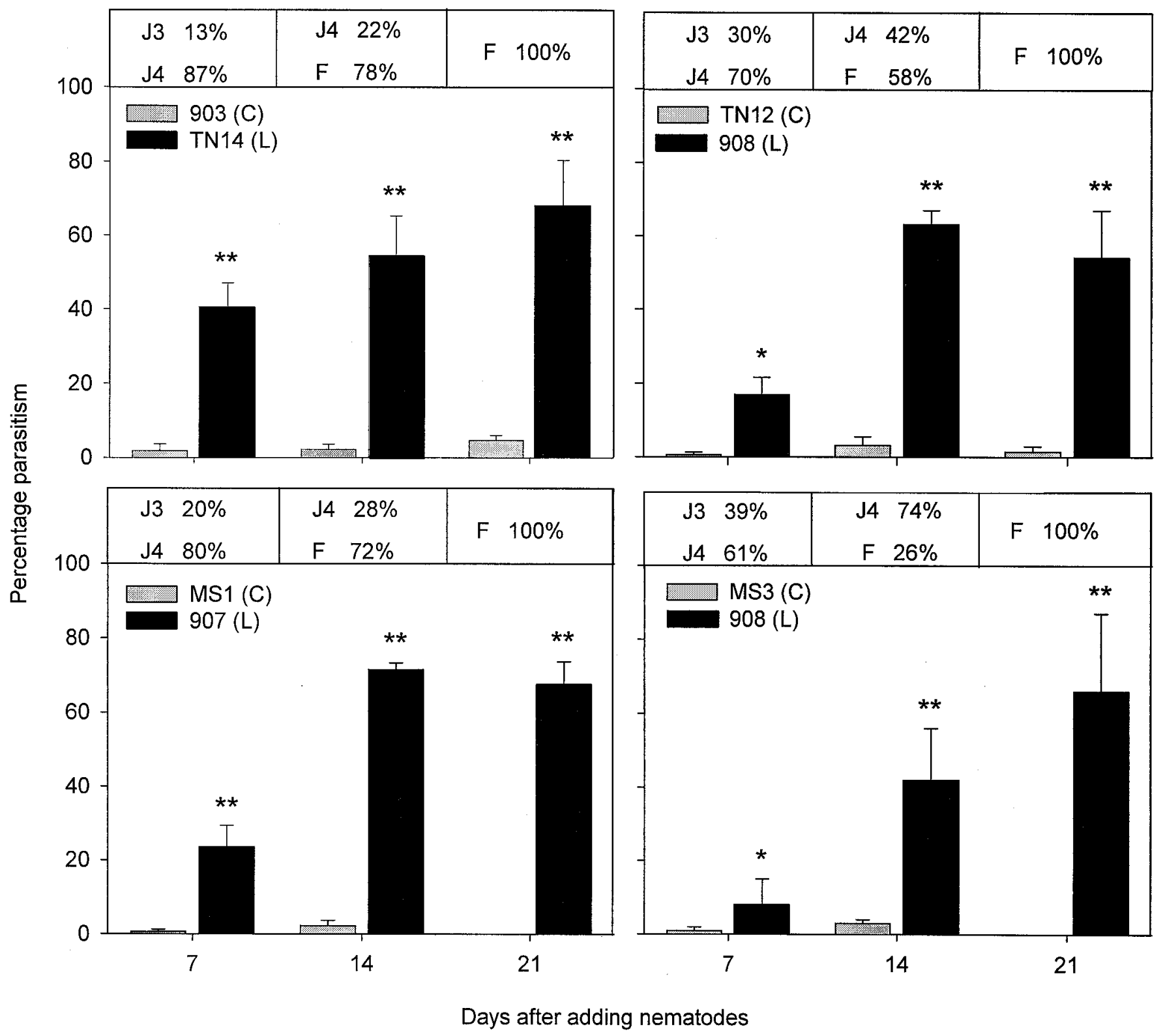

Fig. 2. Parasitism of Heterodera glycines juveniles and females over time in the rhizosphere of soybean by ARF-C and ARF-L isolates. The darker bars are ARF-L isolates (L) and the lighter bars are ARF-C isolates (C). Bars represent the mean percentage \pm standard error (SE) of parasitized nematodes from five replicate pots. Asterisks above bars indicate a difference $(*=P \leq 0.01$, and $* *=P \leq 0.005)$ between ARF-C and ARF-L isolates on that sampling occasion. The percentage of nematodes in each developmental stage (numbers at top of graph) was determined from nematodes extracted from roots in control pots without mycelium. The nematode stages were third- (J3) and fourth-stage (J4) juveniles and females (F). No eggs were observed until day 21. 
an $850-\mu \mathrm{m}$-pore sieve. The number and percentage of individuals in each developmental stage was determined using a dissecting microscope. To determine percent parasitism, 20 to 30 nematodes per pot were hand-picked at random and examined at $\times 200$ to $\times 500$ magnification with a compound microscope for the presence of internal hyphae. If less than 30 individuals were recovered, all were examined. Because of the labor involved in determining parasitism, only one pair of ARF-C and ARF-L isolates were compared in each trial. Nematodes from control pots (without mycelium) were examined for their stage of development, but not for parasitism. These nematodes were used to determine the stage structure of their cohorts in the ARF treatments. The isolate pairs tested were 903 and TN14, TN12 and 908, MS1 and 907, and MS3 and 908. There were five replicate pots per isolate per sampling time, and these were completely randomized on a greenhouse bench. A $t$ test was used to determine differences in the percentage of parasitized individuals between the ARF-C and ARF-L isolates (SAS Institute, Cary, NC).

Parasitism of eggs in the rhizosphere. To facilitate parasitism of $H$. glycines eggs rather than parasitism of prereproductive stages, the nematodes were not exposed to the ARF isolates until egg production had begun. Soybean seedlings were transplanted into 8-cmdiameter pots containing noninfested soil. One week later, a mixture of 3,177 $\pm 225 \mathrm{~J} 2$ and 1,615 \pm 664 eggs was pipetted onto the soil surface of each pot and allowed to develop in roots for 20 days before the soybeans were transplanted into 10 -cm-diameter pots containing ARF-infested soil (3 $\mathrm{mg}$ of mycelium per $\mathrm{cm}^{3}$ ). Control pots contained soil without ARF mycelium. Most $H$. glycines within the roots at transplanting were gravid or pregravid females. Plants were maintained in a greenhouse at 27 to $35^{\circ} \mathrm{C}$ with $4 \mathrm{~h}$ of supplemental light per night and watered twice daily. After 20 days of exposure to the ARF-infested soil, cysts were extracted from the roots and crushed to release eggs as described in the nematode

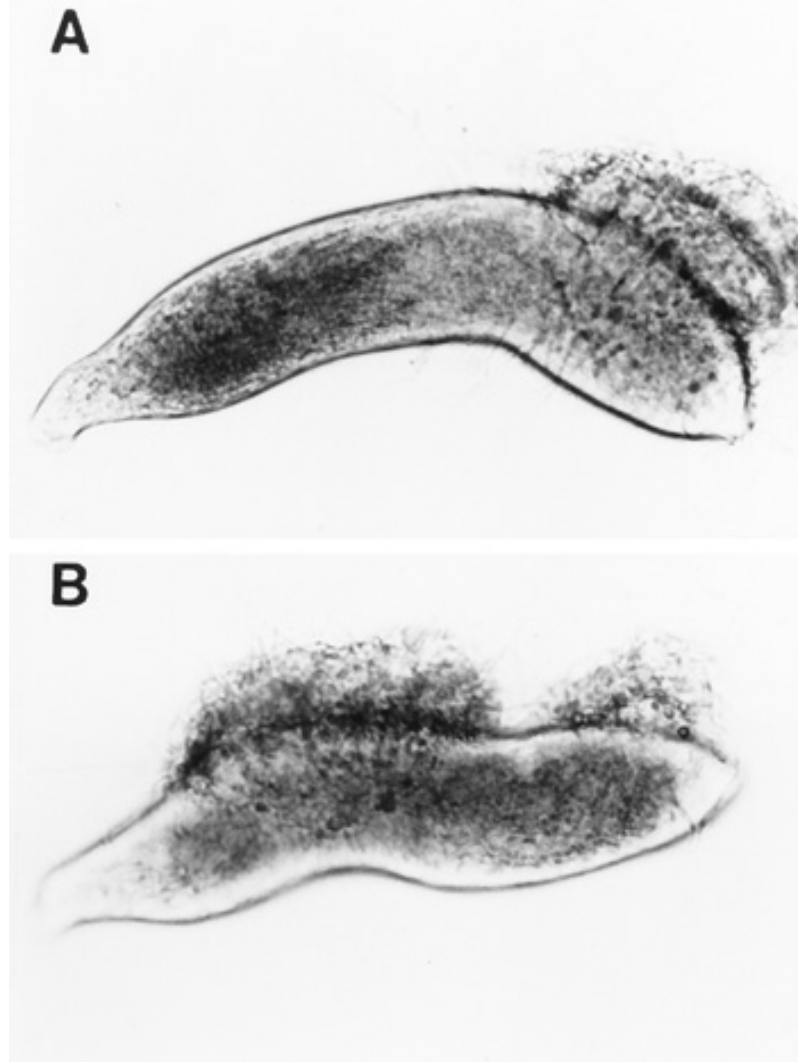

Fig. 3. Fourth-stage juveniles of Heterodera glycines parasitized by the ARF-L isolate 908. Mycelial mats were frequently observed on the surface of infected nematodes. A, Mycelial mat attached near the nematode tail. B, Two mycelial mats: one attached at midbody and the other near the tail of the nematode. methods section. The percentage of parasitized eggs was determined by examining the first 50 eggs encountered from each pot using a compound microscope. Eggs with internal hyphae visible at $\times 200$ to $\times 500$ magnification were counted as parasitized. There were four replicate pots per ARF isolate and control in each trial. The experiment was performed three times with isolates 907, 908, BG2, MS3, TN12, and TN14 included in two trials and isolates 903, KY1, MS1, MS5, and MS8 included in one trial. Differences in nematode parasitism among the isolates were determined using analysis of variance (ANOVA) and Fisher's least significant difference (LSD) test $(P=0.05)$ on proportions transformed by arcsine $\sqrt{ } p$ (SAS Institute).

Mycelial mats in soil. Our ability to quantify growth of ARF in soil is limited because there is no semiselective medium or marker (phenotypic or genetic) for the fungus. However, the fungus produces mycelial mats in heat-treated soil (Fig. 1A and B), which was used in this study as an indicator of relative growth. The mycelial mats were extracted from soil by placing the contents of a $150-\mathrm{cm}^{3}$ pot onto a $850-\mu \mathrm{m}$-pore sieve and agitating the sieve in a bucket of water until most of the soil had passed through. The mycelial mats that were retained on the sieve were rinsed with a gentle stream of water to remove loosely adhering soil particles. Roots, if present, were removed and the mats backwashed into a beaker. The mats from each pot were drained of excess water on a vacuum filter and dried in an oven at $90^{\circ} \mathrm{C}$. Two experiments were performed to compare mycelial mat production among ARF isolates and to determine environmental factors influencing mat biomass. In the first experiment, the biomass of ARF-C and ARF-L isolates was compared in the presence and absence of soybean roots. Heat-treated soil was infested with $3 \mathrm{mg}$ of mycelium per $\mathrm{cm}^{3}$ of soil and added to 10 pots per isolate. A 7-day-old soybean seedling was planted into half the pots of each isolate. Control pots with and without soybean plants were identical to the treatments, except no mycelium was added to the soil. There were three trials of the experiment with different combinations of ARF-C and ARF-L isolates. In the second experiment, the biomass of ARF-C and ARF-L isolates was compared in microwave-heated and nonheated soil. A fine sandy loam soil ( $57 \%$ sand, $27 \%$ silt, and $16 \%$ clay; $<1 \%$ organic matter, $\mathrm{pH}$ 6.4) was collected from a field without $H$. glycines on the University of Arkansas Experiment Station, Fayetteville. Within 1 week of collection, half of the soil was moistened, placed in $500-\mathrm{cm}^{3}$ clay pots, and heated in a microwave oven $(1,500 \mathrm{~W}, 2,450 \mathrm{MHz})$

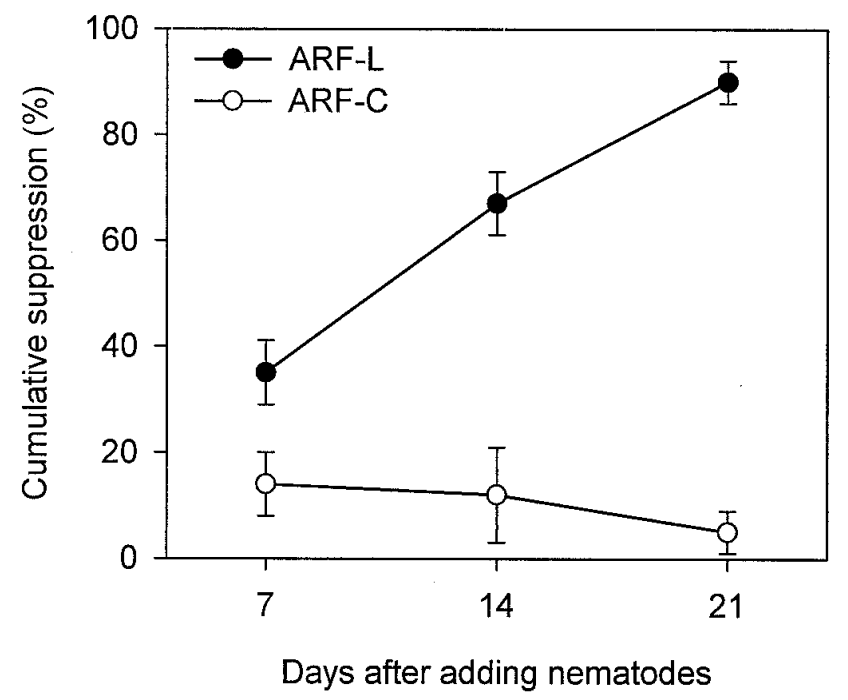

Fig. 4. Cumulative suppression of Heterodera glycines juveniles and females by ARF-C and ARF-L isolates over time. Percent suppression was calculated by $(1-H / T) \times 100$, in which $H=$ the number of noninfected nematodes in ARFinfested pots, and $T=$ the number of nematodes in control pots without ARF mycelium. Data points are the mean \pm standard error of four trials. Each trial included an ARF-C and ARF-L isolate and a control, all replicated five times. 
set at full power for $3 \mathrm{~min}$. Soil temperature reached a maximum of 80 to $90^{\circ} \mathrm{C}$ during heating. Microwave heating of soil reduces the total viable fungal biomass and, to a lesser extent, prokaryote biomass with less release of nutrients than occurs with autoclaving and fumigation (5). Microwave-heated and nonheated soils were air-dried before mixing with mycelium at $3 \mathrm{mg} / \mathrm{cm}^{3}$ of soil. Water without mycelium was mixed into microwave-heated and nonheated soil as controls. Soil was added to five pots $\left(150 \mathrm{~cm}^{3}\right)$ per soil treatment per ARF isolate, and each pot was planted with a 7-day-old soybean seedling. The experiment was conducted twice with isolates 908, BG2, MS5, and TN14. For both experiments, treatments were randomized in a greenhouse at 27 to $35^{\circ} \mathrm{C}$ with $4 \mathrm{~h}$ of supplemental light per night and watered when the soil surface was dry (approximately twice daily for pots with plants and once daily

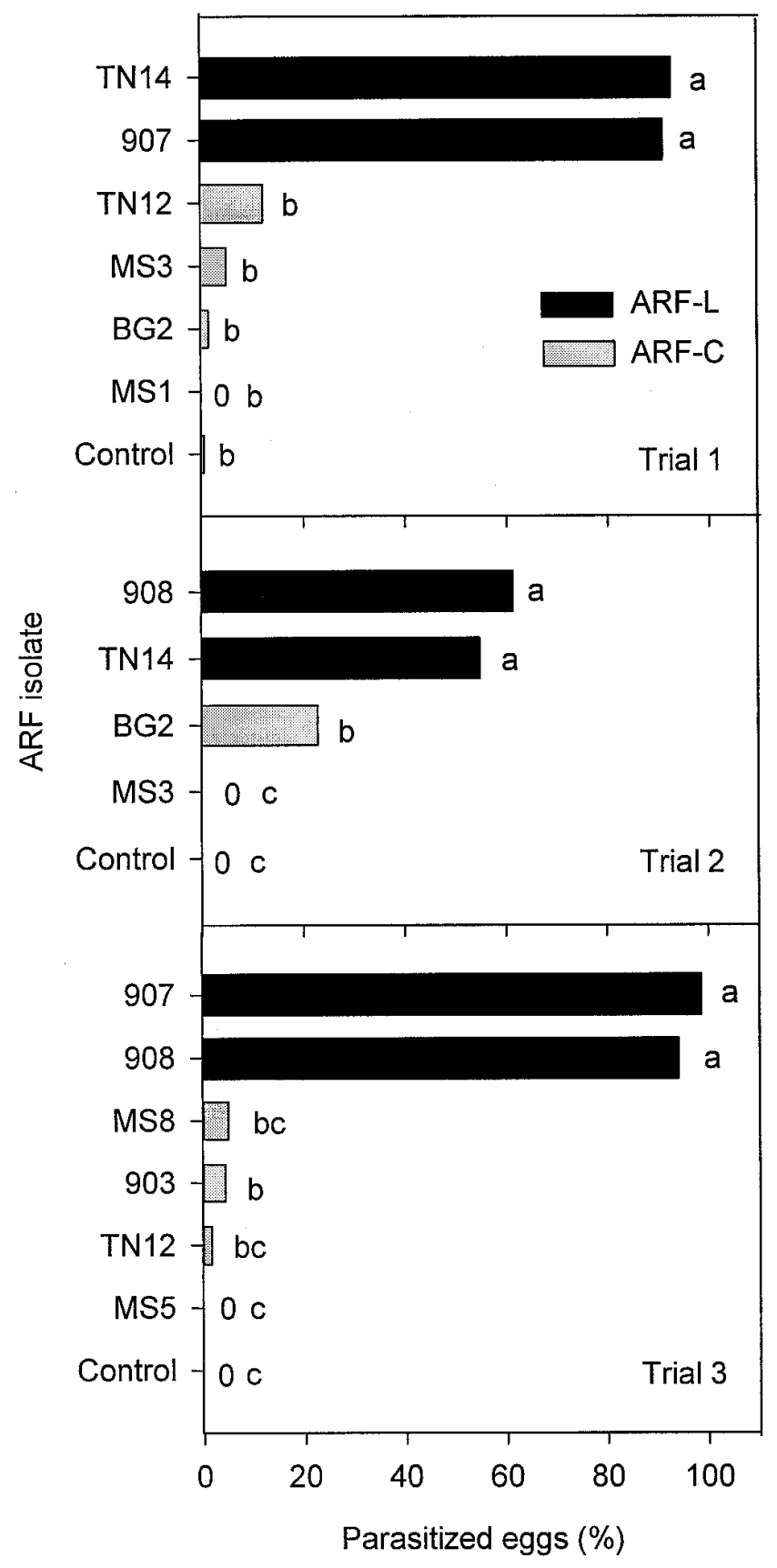

Fig. 5. Parasitism of Heterodera glycines eggs in the rhizosphere of soybean by ARF isolates. Soybeans containing gravid females were transplanted into soil infested with homogenized mycelium. Eggs were extracted 20 days later, and 50 per pot were examined for internal hyphae. Bars represent the mean percentage of parasitized eggs in four replicate pots. Bars with the same letter are not different $(P>0.05)$. for pots without plants). The mats were extracted 10 days after adding the mycelium to soil. For each treatment (with and without plant, microwave-heated and nonheated soil), the average weight of debris from pots without mycelium was subtracted from similarly treated pots with mycelium to determine the weight of mycelial mats per pot. A two-way ANOVA (SAS Institute) was used to determine the effect of ARF isolate and plant and of ARF isolate and soil treatment on mat biomass in the first and second experiments, respectively. Fisher's LSD test $(P=0.05)$ was used to determine differences among isolates.

\section{RESULTS}

Parasitism of eggs on agar. The ability of ARF isolates to parasitize $H$. glycines eggs on YpSs agar differed greatly (Table 1). Six of the eight ARF-C isolates parasitized, on average, more than $50 \%$ of the nematode eggs, whereas the three ARF-L isolates parasitized less than $50 \%$ of the eggs. Less than $1 \%$ of the eggs on the control plugs contained mycelium of unidentified fungi.

Parasitism of sedentary juveniles and females in the rhizosphere. In the control pots without ARF mycelium, the nematode stages within roots were third-stage juveniles (J3) and J4 on day 7 , $\mathrm{J} 4$ and pregravid females on day 14, and gravid females on day 21 (Fig. 2). In pots with added mycelium, ARF-L isolates parasitized more juveniles and females than did ARF-C isolates (Fig. 2). On all sampling occasions, less than $5 \%$ of the individuals were parasitized by the four ARF-C isolates tested. Parasitism in pots with the ARF-L isolates was less ( 8 to $40 \%$ ) in the first week of nematode development than in the second (42 to 72\%) and third (54 to $68 \%$ ) weeks of development. Fungal infection was observed in all sedentary stages: J3, J4, pregravid, and gravid females. Small mycelial mats, similar to those produced on agar and in soil, were attached to the posterior of the nematode, but occasionally were observed at midbody (Fig. 3). No infected J3 were found on day 14 and no infected $\mathrm{J} 4$ were found on day 21, indicating that the cadavers did not persist more than 7 days (i.e., no carryover of infected nematodes from one sampling occasion to another). Cumulative suppression of the nematodes increased over time for the ARF-L isolates (Fig. 4); by 14 days, they had reduced $67 \%$ of juveniles and pregravid females, and by 21 days, reduced $90 \%$ of gravid females when compared with the control without fungus. Suppression did not increase over time for the ARF-C isolates and averaged less than $20 \%$.

Parasitism of eggs in the rhizosphere. In the rhizosphere of soybean, ARF-L isolates parasitized more eggs than did ARF-C isolates (Fig. 5). Parasitism ranged from 55 to $98 \%$ for ARF-L isolates and 0 to $22 \%$ for ARF-C isolates. In the control, less than $0.5 \%$ of the eggs had internal mycelium.

Mycelial mats in soil. Soil debris, usually organic matter, was recovered along with the mycelial mats (Fig. 1B and C). In pots without ARF mycelium, the dry weight of debris averaged $0.84 \pm$ $0.21 \mathrm{~g}( \pm \mathrm{SE})$ in the first experiment and $4.23 \pm 0.48 \mathrm{~g}$ in the second

TABLE 2. Effect of soybean roots and heating soil on the biomass of mycelial mats of a sterile fungus (ARF)

\begin{tabular}{lccc}
\hline & \multicolumn{3}{c}{$\begin{array}{c}\text { Dry weight }(\mathrm{g}) \text { of mycelial mats } \\
\text { and level of significance }\end{array}$} \\
\cline { 2 - 4 } Treatment & Trial 1 & Trial 2 & Trial 3 \\
\hline Experiment 1 & & & \\
$\quad$ Plant & 3.49 & 3.97 & 1.50 \\
$\quad$ No plant & 3.14 & 2.32 & 1.84 \\
$P$ value & 0.15 & 0.01 & 0.003 \\
Experiment 2 & & & \\
$\quad$ Microwave-heated soil & 6.88 & 1.63 & \\
$\quad$ Nonheated soil & 3.32 & 1.96 & \\
$P$ value & 0.01 & 0.20 & \\
\hline
\end{tabular}

${ }^{a}$ Weight of mycelial mats averaged across all isolates. There was no interaction between isolate and plant (experiment 1) or isolate and soil treatment (experiment 2). 
experiment. In addition to the larger soil debris, small soil particles adhered to the mycelial mats. These soil particles could not be rinsed from the mycelium and, therefore, contributed to the final dry weight of the mycelial mats. In the first experiment, soybean roots inconsistently affected the biomass of mycelial mats in soil (Table 2). There were always a few mats attached to roots; however, most were recovered from the bulk soil. In the first trial, the number of mats attached to the roots from each pot were counted and were positively correlated with mycelial biomass in soil $(P=$ $0.0001, R=0.66)$. The greatest number of mats per root system was $25 \pm 5$ and $17 \pm 2$ for isolates 908 and TN14, respectively. In the second experiment, the biomass of mycelial mats was greater in microwave-heated than in nonheated soil in the first trial, but similar in the second trial (Table 2). In both experiments, ARF-L isolates generally produced a greater biomass of mats than did ARF-C isolates (Figs. 6 and 7). There were no interactions be-

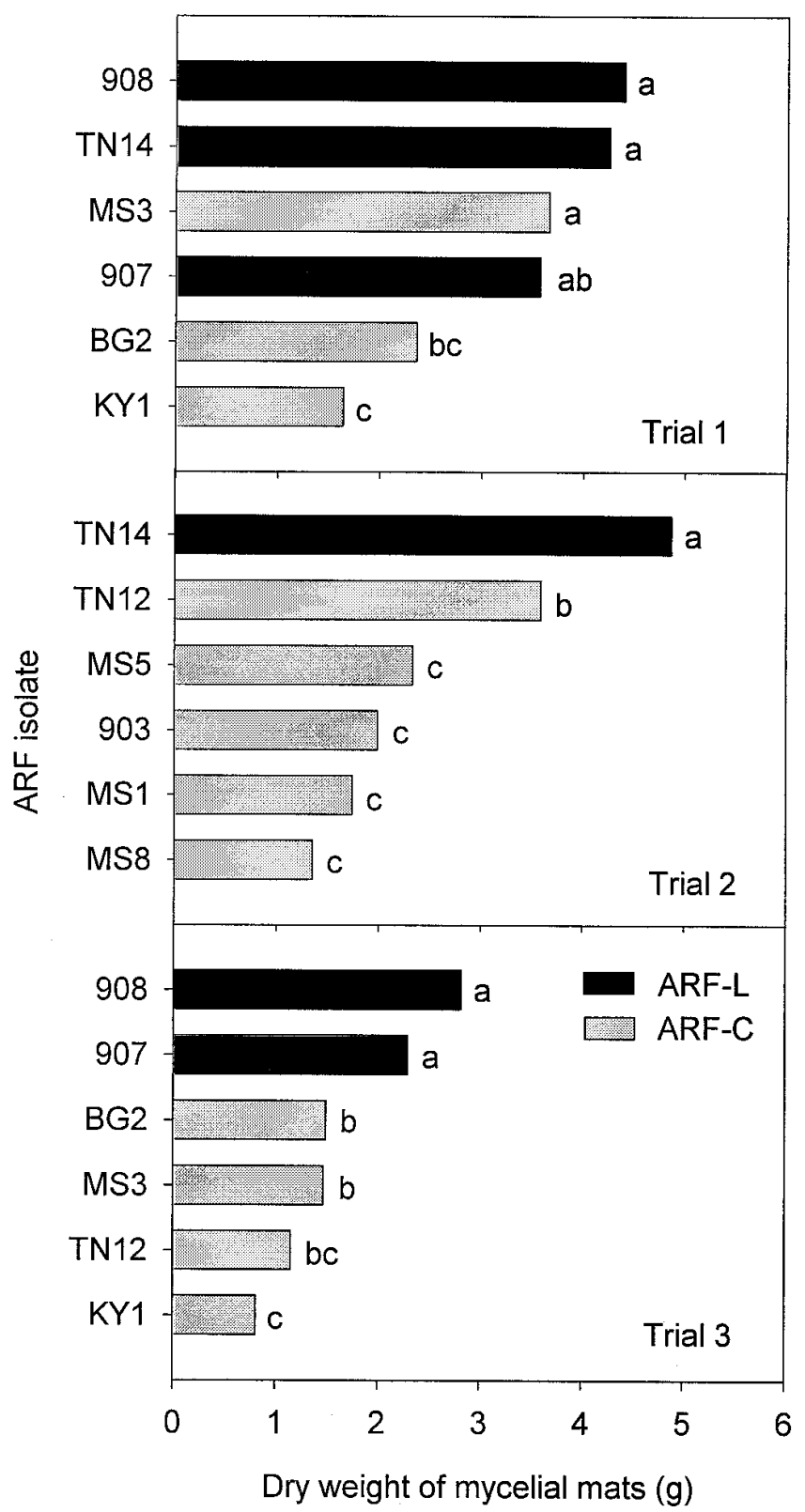

Fig. 6. Production of mycelial mats in soil by isolates of ARF. Homogenized mycelium ( $3 \mathrm{mg} / \mathrm{cm}^{3}$ of soil) was mixed into heat-treated soil. Mats were extracted from soil 10 days later. Bars represent the mean of $10150-\mathrm{cm}^{3}$ pots (five each with and without soybean plants) minus the weight of debris extracted from similarly treated pots without mycelium. Bars with the same letter are not different $(P>0.05)$. tween the ARF isolates and either the plant or soil treatments. For example, growth of mycelial mats was suppressed equally for all the isolates in nonheated compared with microwave-heated soil.

\section{DISCUSSION}

Our results support those of Kim et al. (14), who reported that, on three different agar media, the ARF-L isolates were relatively weak egg parasites compared with the ARF-C isolates. Two ARF-C isolates, MS8 and 903, were weaker egg parasites in our study than was previously reported (14). Perhaps the virulence of these isolates has attenuated over time or the different media used in their study and ours affected parasitism. Culture medium can influence the percentage of eggs parasitized. The ARF-L isolates, which parasitized only $17 \pm 5 \%(\overline{\times} \pm \mathrm{SE})$ of the eggs on cornmeal agar, parasitized $45 \pm 9 \%$ of the eggs on potato dextrose agar (14). It is not clear whether the medium influences virulence of the isolates or susceptibility of the nematode eggs.

The ARF isolates are apparently not specialized for parasitizing different stages of $H$. glycines. The ARF-L isolates parasitized a high proportion of eggs, juveniles, and females, whereas the ARF-C isolates parasitized only a small proportion of these stages in the rhizosphere of soybean. Other parasites of nematodes such as Paecilomyces lilacinus, Verticillium chlamydosporium, V. lecanii, and a sterile dematiaceous fungus are able to infect both eggs and females of cyst and root-knot nematodes $(7,8,10,16)$. However, because juveniles and young females are considered less vulnerable than are eggs to infection, few researchers have determined rates

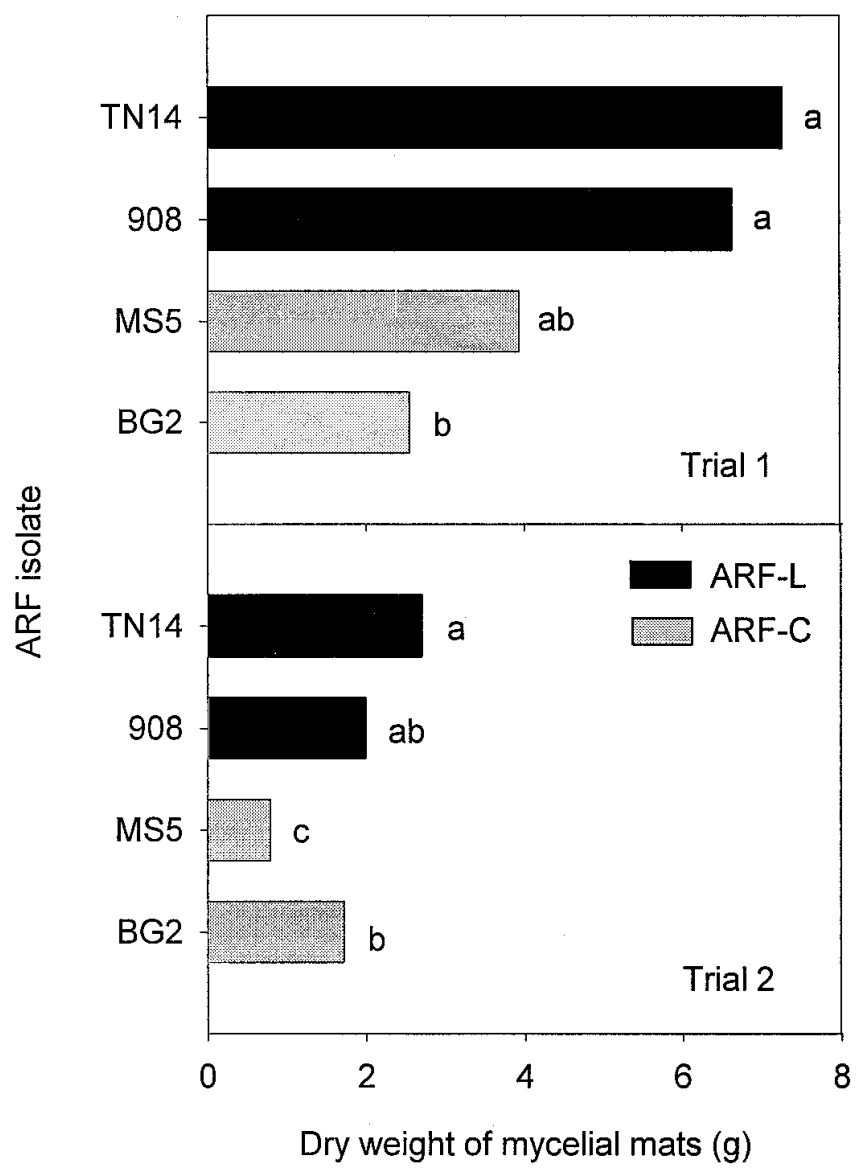

Fig. 7. Production of mycelial mats in soil by isolates of ARF. Homogenized mycelium ( $3 \mathrm{mg} / \mathrm{cm}^{3}$ of soil) was mixed into either microwave-heated or nonheated soil. Mats were extracted from soil 10 days later. Bars represent the mean of $10150-\mathrm{cm}^{3}$ pots (five each with microwave-heated and nonheated soil) minus the weight of debris extracted from similarly treated pots without mycelium. Bars with the same letter are not different $(P>0.05)$. 
of parasitism of these stages in the rhizosphere. Many J3 and J4 stages of cyst nematodes are completely embedded within the root cortex, where they are thought to be protected from soilborne parasites such as ARF $(6,8,18)$. Yet, in soil infested with ARF-L isolates, these stages were frequently parasitized. The fungus apparently initiates infection of juveniles and females by forming a mycelial mat on the surface of the nematode and then penetrates the cuticle from various points under the mat in a manner similar to that described for penetration of cysts (15). We typically observed these mats at the posterior end of $\mathrm{J} 3$ and $\mathrm{J} 4$, though a few were formed at midbody. Some J3 and J4 may not be embedded within the root tissue. Steele (17) observed male J2, J3, and J4, and occasionally female J4 of $H$. schachtii developing ectoparasitically on roots of sugar beet and tomato. Because the parasitized nematodes were not examined in situ, we were unable to determine whether the fungus parasitized only nematodes on the root surface or whether it sometimes entered the root and parasitized nematodes within.

The ARF-C isolates were aggressive parasites of nematode eggs in vitro, but parasitized few eggs in the rhizosphere of soybean; the ARF-L isolates, on the other hand, were comparatively weak parasites of nematode eggs in vitro, but parasitized a high percentage of eggs in the rhizosphere. We hypothesized that the ARF-L isolates parasitized more eggs in the rhizosphere because they were able to proliferate to a greater extent in the soil than were the ARF$\mathrm{C}$ isolates. In the absence of any selective media or markers for ARF, we used the biomass of mycelial mats as an indicator of relative growth in soil. The biomass of mats will likely influence contact with roots in that larger or more numerous mats will have a greater probability of contacting a developing root system than will smaller or less numerous mats. The ARF-L isolates generally produced a greater biomass of mycelial mats than did the ARF-C isolates, which may explain, in part, differences in parasitic efficiency between the two groups. However, differences in mat biomass between ARF-C and ARF-L isolates were not as extreme as were differences in percentage of parasitized eggs. In addition to mats, the ARF isolates may have produced diffuse mycelium that was not extracted from the soil. Diffuse mycelium may originate from the mats or from colonized organic matter in soil. The extent of this diffuse growth in bulk or rhizosphere soil was not measured, and it is not known if the ARF-L and ARF-C isolates differ in total mycelial biomass (mats plus diffuse mycelium).

The formation of mycelial mats in nonsterilized soil without nematodes implies that ARF can grow saprophytically in soil. However, much remains to be learned about the biology of this fungus as a soil saprophyte. For example, it is unclear what ARF is using as a nutrient source in soil without nematodes or plant roots; perhaps it is utilizing organic debris such as old plant material and dead fauna and flora as a substrate for growth. Moreover, the results of our experiment on the effect of soybean roots on the biomass of mycelial mats were inconclusive. The high rates of egg parasitism (55 to 98\%) that we observed 20 days after transplanting soybeans containing young females into soil infested with ARF-L isolates suggests that the fungus is able to efficiently colonize soybean roots. Yet, we were unable to find a strong association of mats with roots in the absence of $H$. glycines. The presence of nematodes in the roots may stimulate root colonization, as is the case with the nematophagous fungus $V$. chlamydosporium (2).

The ability of ARF-L isolates to parasitize a large percentage of both prereproductive stages and eggs of $H$. glycines may contribute to the organism's effectiveness as a biological control agent. In a study similar to ours, suppression of $H$. schachtii by isolates of
$V$. chlamydosporium was related to the percentage of young females that were infected (10). One isolate reduced the number of females per plant by $80 \%$ and also parasitized $79 \%$ of the eggs produced by the remaining females (11). In our search for potential biological control agents of cyst nematodes, more effort should be directed at identifying isolates capable of aggressively parasitizing both prereproductive stages and eggs in the rhizosphere of plants.

\section{ACKNOWLEDGMENTS}

We thank A. W. Johnson, B. R. Kerry, S. L. F. Meyer, and D. R. Sumner for their helpful comments during the preparation of this manuscript.

\section{LITERATURE CITED}

1. Bridge, J., Page, S., and Jordon, S. 1982. An improved method for staining nematodes in roots. Page 171 in: Report of the Rothamsted Experiment Station for 1981, Part 1. Rothamsted Experimental Station, Harpenden, England.

2. De Leij, F. A. A. M., Kerry, B. R., and Dennehy, J. A. 1992. The effect of fungal application rate and nematode density on the effectiveness of Verticillium chlamydosporium as a biological control agent for Meloidogyne incognita. Nematologica 38:112-122.

3. Emerson, R. 1958. Mycological organization. Mycologia 50:589-621.

4. Endo, B. Y. 1964. Penetration and development of Heterodera glycines in soybean roots and related anatomical changes. Phytopathology 54:79-88.

5. Ferriss, R. S. 1984. Effects of microwave oven treatment on microorganisms in soil. Phytopathology 74:121-126.

6. Gintis, B. O., Morgan-Jones, G., and Rodriguez-Kabana, R. 1983. Fungi associated with several developmental stages of Heterodera glycines from an Alabama soybean field soil. Nematropica 13:181-200.

7. Hojat Jalali, A. A., and Coosemans, J. 1997. Efficacy of a sterile fungus, $\mathrm{CH} 1-1$, as a new biocontrol agent for sugar beet cyst nematode, Heterodera schachtii. Meded. Fac. Landbouwwet. Rijksuniv. Gent 62:721-735.

8. Jatala, P. 1986. Biological control of plant-parasitic nematodes. Annu. Rev. Phytopathol. 24:453-489.

9. Jenkins, W. R. 1964. A rapid centrifugal-flotation technique for separating nematodes from soil. Plant Dis. Rep. 48:692.

10. Kerry, B. R. 1988. Two microorganisms for the biological control of plant parasitic nematodes. Pages 603-607 in: Proc. Brighton Crop Prot. Conf. Pests Dis., Vol. 2. British Crop Protection Council, London.

11. Kerry, B. R. 1990. An assessment of progress toward microbial control of plant-parasitic nematodes. J. Nematol. 22:621-631.

12. Kim, D. G., and Riggs, R. D. 1991. Characteristics and efficacy of a sterile hyphomycete (ARF18), a new biocontrol agent for Heterodera glycines and other nematodes. J. Nematol. 23:275-282.

13. Kim, D. G., and Riggs, R. D. 1995. Efficacy of the nematophagous fungus ARF18 in alginate-clay pellet formulations against Heterodera glycines. J. Nematol. 27:602-608.

14. Kim, D. G., Riggs, R. D., and Correll, J. C. 1998. Isolation, characterization, and distribution of a biocontrol fungus from cysts of Heterodera glycines. Phytopathology 88:465-471.

15. Kim, D. G., Riggs, R. D., and Kim, K. S. 1992. Ultrastructure of Heterodera glycines parasitized by Arkansas fungus 18. Phytopathology 82: 429-433.

16. Meyer, S. L. F., and Wergin, W. P. 1998. Colonization of soybean cyst nematode females, cysts, and gelatinous matrices by the fungus Verticillium lecanii. J. Nematol. 30:436-450.

17. Steele, A. E. 1971. Orientation and development of Heterodera schachtii larvae on tomato and sugarbeet roots. J. Nematol. 3:424-426.

18. Stirling, G. R. 1991. Biological Control of Plant Parasitic Nematodes: Progress, Problems and Prospects. CAB International, Wallingford, England.

19. Tefft, P. M., and Bone, L. W. 1984. Zinc-mediated hatching of eggs of soybean cyst nematode, Heterodera glycines. J. Chem. Ecol. 10:361-372.

20. Timper, P., and Riggs, R. D. 1998. Variation in efficacy of isolates of the fungus ARF against the soybean cyst nematode, Heterodera glycines. J. Nematol. 30:461-467.

21. Wharton, D. A. 1986. A Functional Biology of Nematodes. Johns Hopkins University Press, Baltimore, MD. 